\title{
Tofacitinib: Real-World Data and Treatment Persistence in Rheumatoid Arthritis
}

\author{
Ilaria Bertoldi ${ }^{1}$ \\ Roberto Caporali ${ }^{2}$ \\ 'Medical Department, Pfizer Italy, Rome, \\ Italy; ${ }^{2}$ Department of Clinical Sciences \\ and Community Health, University of \\ Milan and ASST Pini-CTO Hospital, Milan, \\ Italy
}

\begin{abstract}
Tofacitinib is an oral Janus kinase (JAK) inhibitor indicated for the treatment of rheumatoid arthritis (RA). The efficacy and safety/tolerability of tofacitinib have been extensively evaluated as monotherapy and combination therapy in multiple, randomised, multicentre studies in patients with RA. Tofacitinib as monotherapy (as first- and second-line treatment) or as combination with methotrexate (MTX) or other csDMARDs as second- and third-line treatment is effective and generally well tolerated in patients with RA. This article focuses on recent real-world evidence investigating the effectiveness, treatment persistence and safety/tolerability of tofacitinib in patients with RA. With this purpose, a literature review was conducted from April 2018 up to October 2020 for the effectiveness, persistence and safety of tofacitinib for the treatment of RA, primarily focusing on real-world studies. These retrospective and prospective and observational studies demonstrate the effectiveness of tofacitinib, thus supporting pivotal data from the clinical trial programme. Treatment persistence was generally comparable to that of biologic disease-modifying anti-rheumatic drugs. Safety findings in these observational studies were consistent with the known safety profile of the approved dose of $5 \mathrm{mg}$ twice daily.
\end{abstract}

Keywords: rheumatoid arthritis, real-world, effectiveness, persistence

\section{Introduction}

Recent EULAR recommendations for the management of rheumatoid arthritis (RA) state that following failure of 1 or more conventional synthetic disease-modifying anti-rheumatic drug (csDMARD) and in the presence of at least one poor prognostic factor, a Janus kinase (JAK) inhibitor or a biological DMARD (bDMARD) should be started. ${ }^{1}$ Tofacitinib is an oral JAK inhibitor for the treatment of RA. In cellular settings where JAKs signal in pairs, tofacitinib preferentially inhibits signalling by heterodimeric receptors associated with JAK1 and/or JAK3 and has functional selectivity over JAK2. ${ }^{2,3}$

The efficacy and safety/tolerability of tofacitinib have been extensively evaluated as monotherapy and combination therapy in multiple 6- to 24-month, randomised, double-blind, multicentre, Phase 3 or 3b/4 Oral Rheumatoid Arthritis (ORAL) studies in patients with RA. The findings from these controlled trials demonstrate that tofacitinib monotherapy (as first- and second-line treatment) and in combination with methotrexate (MTX) or other csDMARDs as second- and third-line treatment is effective and generally well tolerated in patients with RA. ${ }^{4-11}$

The open-label ORAL Sequel long-term extension study presented efficacy data for up to 8 years and safety data for up to 9.5 years on 4481 RA patients and a total tofacitinib exposure of 16,291 patient-years. $^{12}$ Tofacitinib maintained American
Correspondence: Roberto Caporali Department of Clinical Sciences and Community Health, University of Milan and ASST Pini-CTO Hospital, Milan, Italy Email roberto.caporali@unimi.it 
College of Rheumatology-20\% $\left(\mathrm{ACR}_{20}\right),-50 \%\left(\mathrm{ACR}_{50}\right)$ and $-70 \%\left(\mathrm{ACR}_{70}\right)$ response rates between months 1 and 96 , and efficacy was generally similar for $5 \mathrm{mg}$ twice daily (BID) (months 1 to 96) and $10 \mathrm{mg}$ BID (months 1 to 72). Tofacitinib (5 mg and $10 \mathrm{mg}$ BID) reduced mean erythrocyte sedimentation rate (ESR)-based disease activity score assessed in 28 joints (DAS28-ESR) and improved mean Health Assessment Questionnaire Disability Index (HAQDI) scores at month 1; both DAS28-ESR and HAQ-DI scores remained stable during 96 months of treatment. Clinical Disease Activity Index (CDAI) and Simple Disease Activity Index (SDAI)-defined remission were obtained in about one-third of patients at month 96 .

Tofacitinib administered as monotherapy or combination therapy showed a consistent safety profile. ${ }^{12}$ The incidence rate for AEs leading to discontinuation was 6.8 patients per 100 patient-years. For all-cause AEs of special interest, the incidence rate was 3.4 per 100 patient-years for herpes zoster, and was lower for serious infections (2.4/100 patient-years), malignancies excluding nonmelanoma skin cancer (NMSC; 0.8/100 patient-years), major adverse cardiovascular events $(0.4 / 100$ patientyears) and all-cause mortality (0.3/100 patient-years). Most all-cause AEs for tofacitinib were mild (59\%) or moderate $(36 \%)$ in severity, and proportions of mild and moderate all-cause AEs were similar for patients receiving tofacitinib $5 \mathrm{mg}$ or $10 \mathrm{mg}$ BID.

Observational studies and data collections from registries provide real-world evidence of therapies and complement randomised controlled trials (RCTs) as they provide invaluable information about routine clinical practice. ${ }^{13-15}$ This review focuses on recent real-world evidence investigating the effectiveness, treatment persistence and safety/ tolerability of tofacitinib in patients with RA, available since the review by Caporali \& Zavaglia in 2019. ${ }^{16}$

\section{Methods}

For the purposes of this narrative review, PubMed was searched on 23rd October 2020 using the search terms "tofacitinib" and "rheumatoid arthritis" and limited to articles published from April 2018 up to October 2020. A total of 290 articles were assessed for relevance, focusing on real-world studies; long-term extension and economic studies were also found and evaluated if pertinent. Abstracts from ACR, European League Against Rheumatism (EULAR), and Asia Pacific League of Associations for Rheumatology (APLAR) meetings from 2018 to 2020 were also searched, since these often present the first reports and most up-to-date experience with drug therapy. The publications were subgrouped by those evaluating effectiveness and/or persistence and/or safety.

\section{Results \\ Effectiveness and/or Persistence}

Two real-world studies which analysed claims database or registry data reported only effectiveness outcomes. ${ }^{17,18}$ Interrogation of US MarketScan ${ }^{\circledR}$ databases over a threeyear period (2011-2014) showed similar effectiveness rates for tofacitinib and non-TNFi biologics. In a retrospective cohort analysis of MarketScan ${ }^{\circledR}$ databases involving $21,832 \mathrm{RA}$ patients ( $0.8 \%$ receiving tofacitinib), six strict criteria were used to define effective therapy. ${ }^{17}$ After one year, therapeutic effectiveness was $15.4 \%$ for tofacitinib, compared to $18.6 \%$ for TNFi, $19.8 \%$ for nonTNFi biologics and $11.1 \%$ for csDMARDs. Analysis of the US Corrona RA registry compared outcomes in patient cohorts receiving TNFi $(n=8014)$ or tofacitinib $(n=558)$ with/without MTX. ${ }^{18}$ Effectiveness was assessed by CDAI-based low disease activity (LDA)/remission and modified $\mathrm{ACR}_{20}$ response rate. Tofacitinib as monotherapy or in combination achieved an efficacy similar to TNFi in combination with MTX in the third/fourth line, while association with MTX improved efficacy of TNFi in the second/third line.

Fourteen studies reported on the effectiveness and/or persistence of tofacitinib (Table 1). A retrospective study of US insurance claims databases compared patients who switched from adalimumab or etanercept to tofacitinib ( $\mathrm{n}=$ 549 ) with those switching from adalimumab to etanercept or conversely from etanercept to adalimumab $(\mathrm{n}=191) .{ }^{19}$ Patients who switched from adalimumab to tofacitinib had significantly higher persistence (defined as persistence without a $\geq 60$-day gap in index therapy or switch) and longer duration of therapy.

Thanks to the real-world collection in the US, information was obtained about two formulations of tofacitinib-modifiedrelease (MR) $11 \mathrm{mg}$ daily (QD) and immediate-release (IR) $5 \mathrm{mg}$ twice daily (BID) - which were compared for effectiveness and adherence of patients initiating either product following interrogation of US claims databases $(n=1057)$ and the Corrona US RA Registry $(n=450)^{20}$ (in 2016, in US, an extended-release dose of tofacitinib $11 \mathrm{mg}$ once daily was approved). Assessed using clinical disease activity after 6 months of treatment, effectiveness was similar between the two formulations. Adherence was significantly higher with 


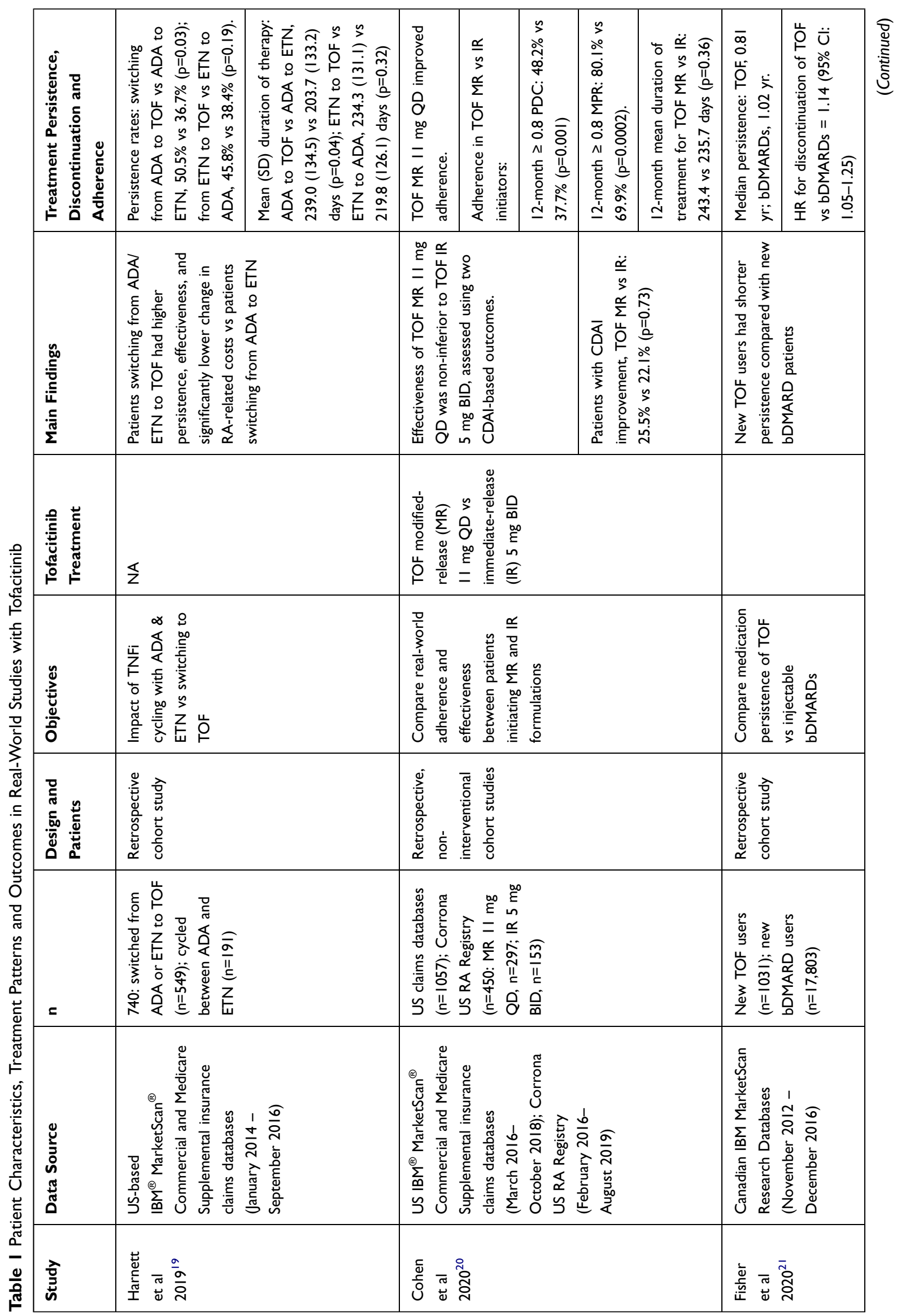




\begin{tabular}{|c|c|c|c|c|}
\hline 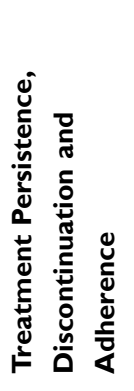 & 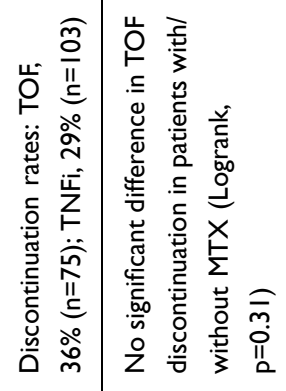 & 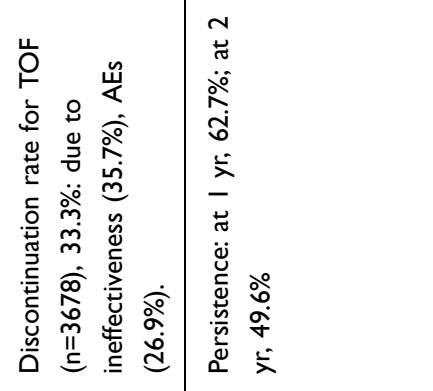 & 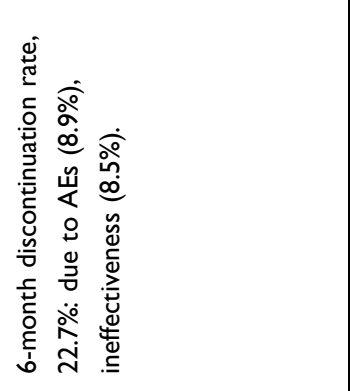 & 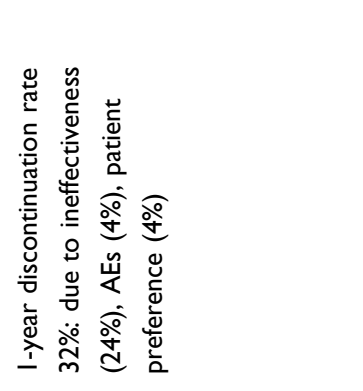 \\
\hline 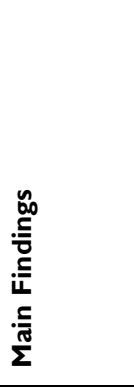 & 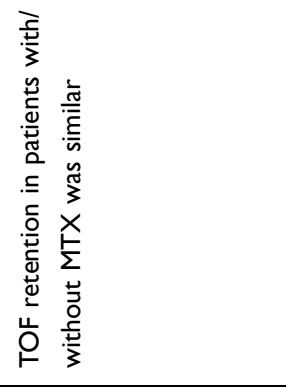 & 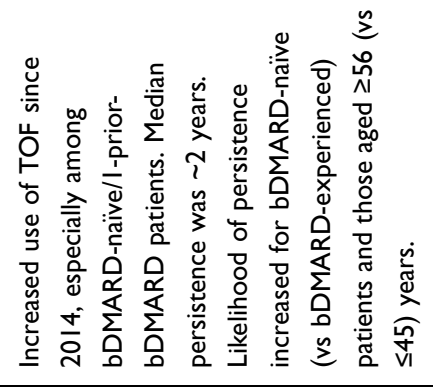 & 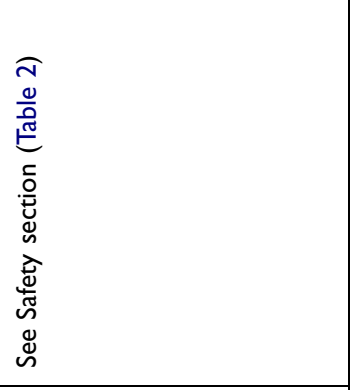 & 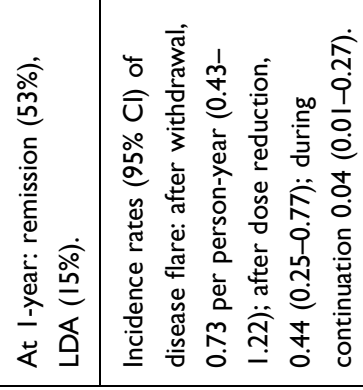 \\
\hline 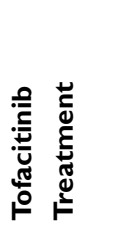 & $\mathbb{z}$ & 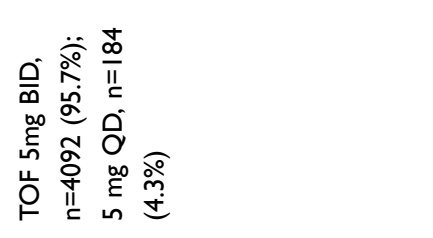 & & 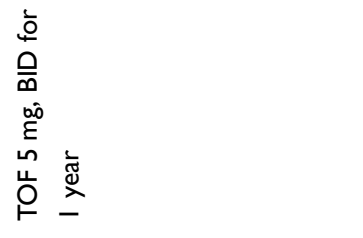 \\
\hline & 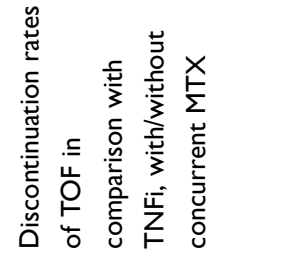 & 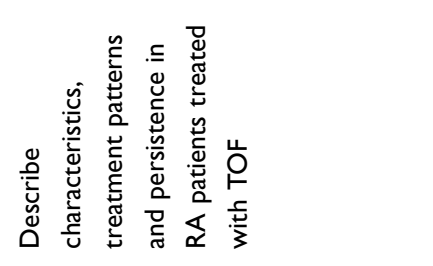 & 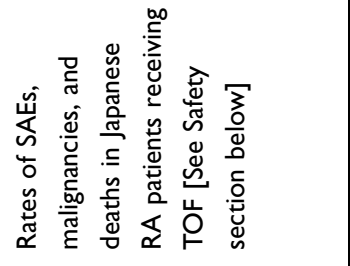 & 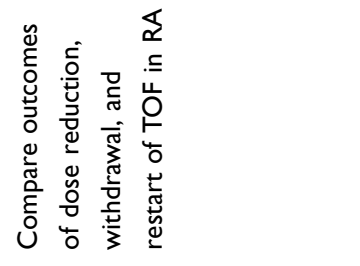 \\
\hline 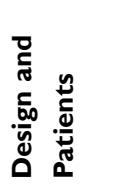 & 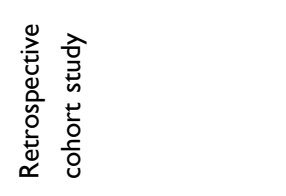 & 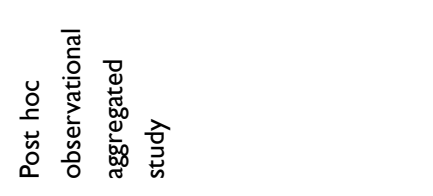 & 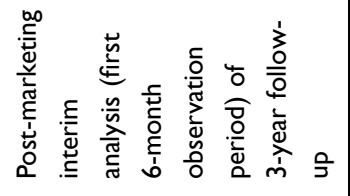 & 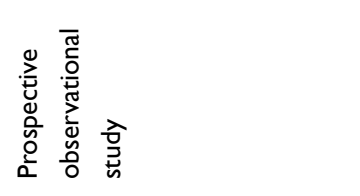 \\
\hline$=$ & 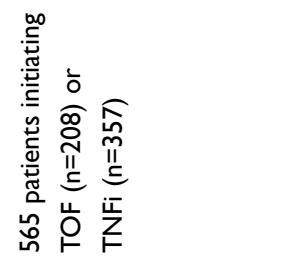 & 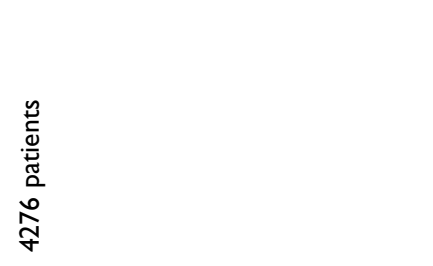 & స్రి & $\underline{\text { 음 }}$ \\
\hline 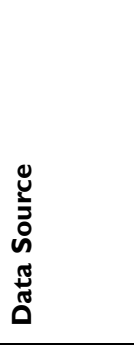 & 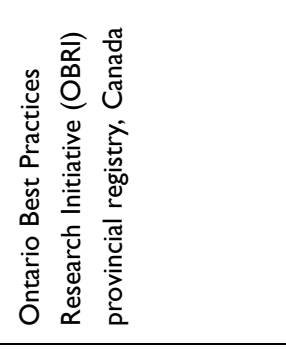 & 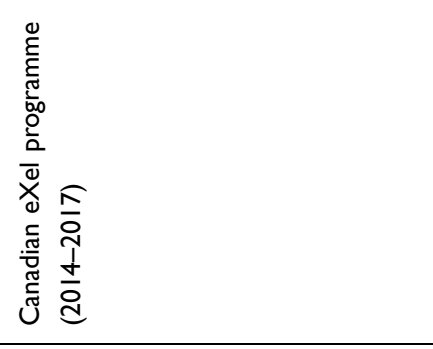 & 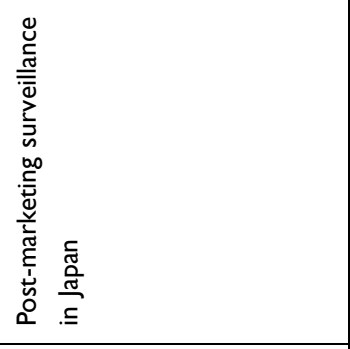 & 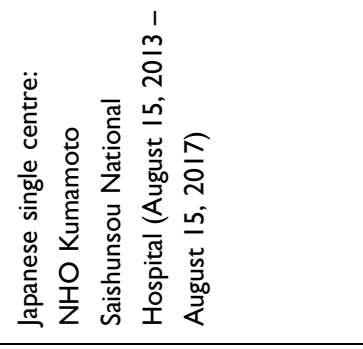 \\
\hline 䓂 & 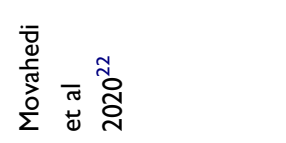 & 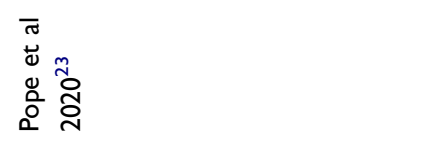 & 苟 & 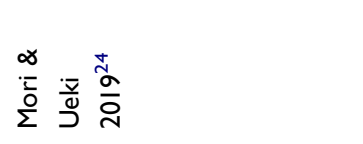 \\
\hline
\end{tabular}




\begin{tabular}{|c|c|c|c|c|c|c|c|}
\hline 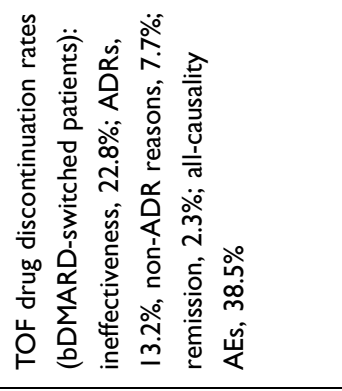 & 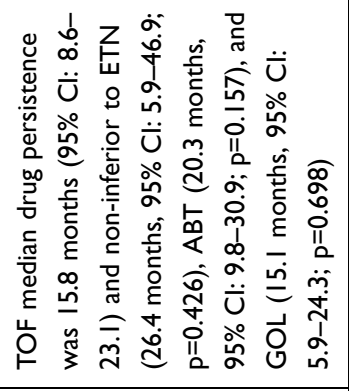 & 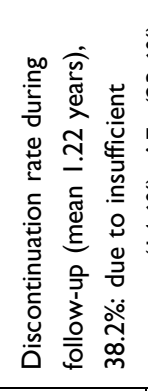 & & 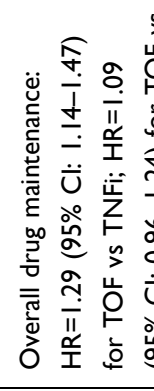 & 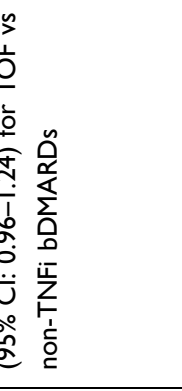 & 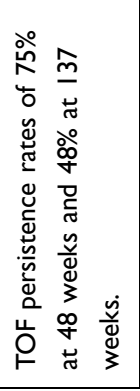 & 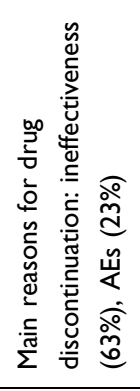 \\
\hline 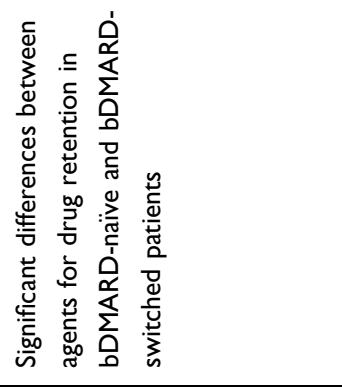 & 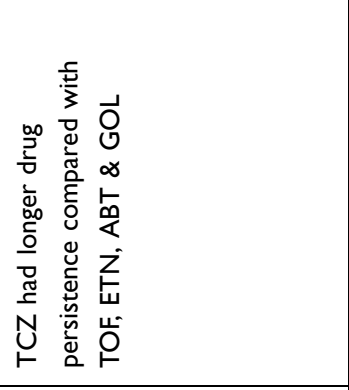 & 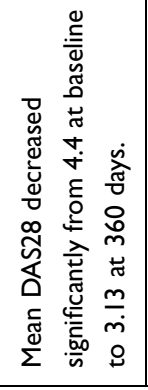 & 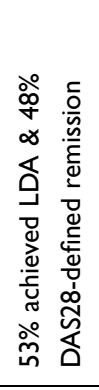 & \multicolumn{2}{|c|}{ 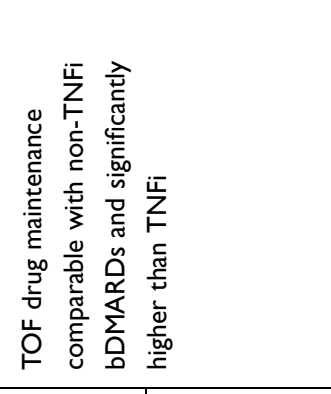 } & \multicolumn{2}{|l|}{ 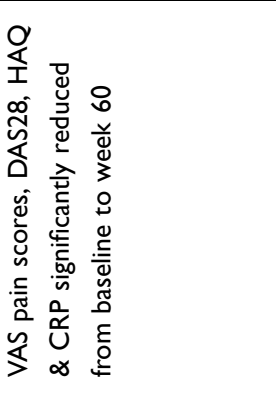 } \\
\hline $\mathbb{Z}$ & & \multicolumn{2}{|l|}{ 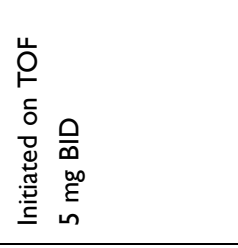 } & 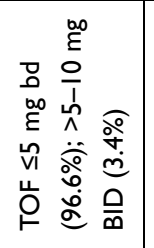 & 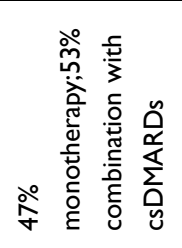 & $\mathbb{Z}$ & \\
\hline 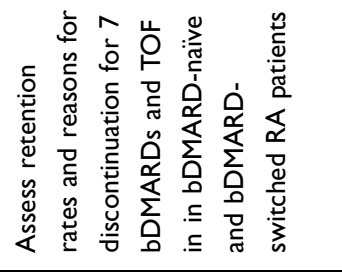 & 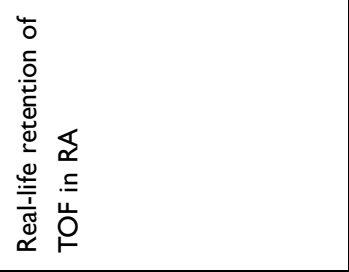 & \multicolumn{2}{|l|}{ 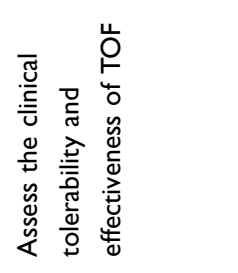 } & \multicolumn{2}{|l|}{ 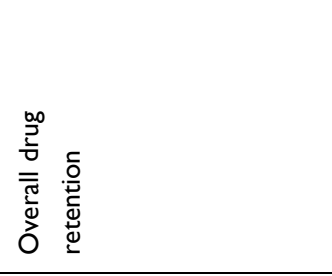 } & \multicolumn{2}{|c|}{ 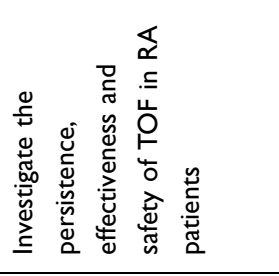 } \\
\hline 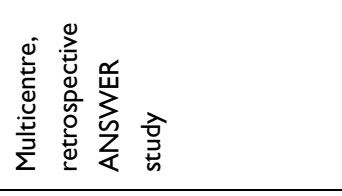 & 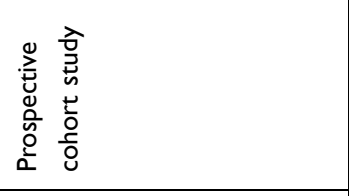 & \multicolumn{2}{|l|}{ 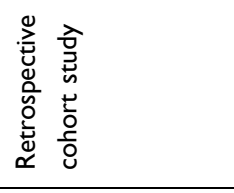 } & \multicolumn{2}{|l|}{ 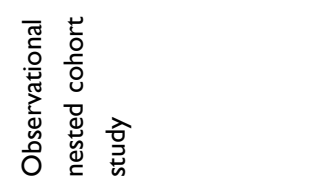 } & \multicolumn{2}{|l|}{ 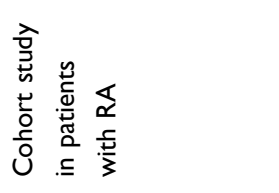 } \\
\hline 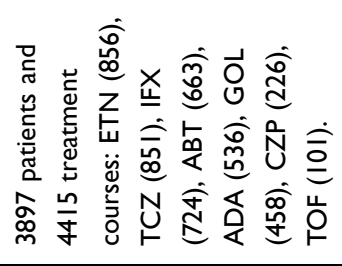 & 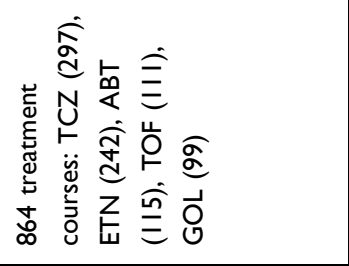 & \multicolumn{2}{|l|}{$\stackrel{\Xi}{ \pm}$} & \multicolumn{2}{|c|}{ 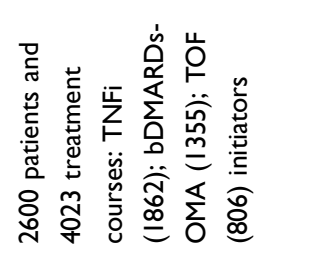 } & \multicolumn{2}{|l|}{$\stackrel{\propto}{\infty}$} \\
\hline 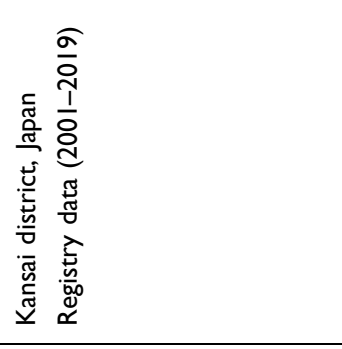 & 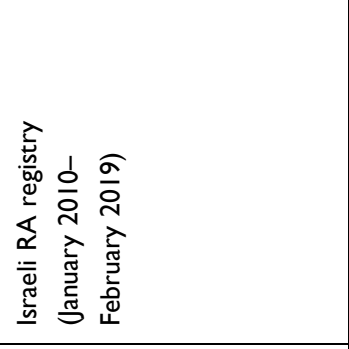 & \multicolumn{2}{|l|}{ 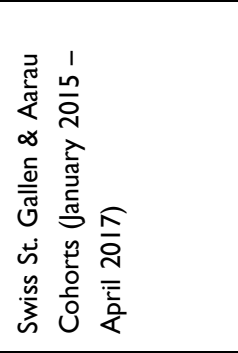 } & \multicolumn{2}{|c|}{ 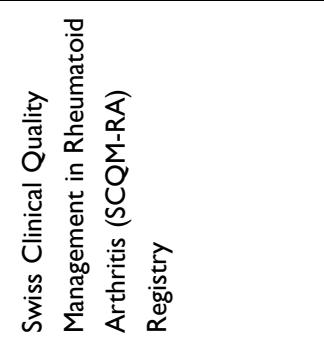 } & \multicolumn{2}{|l|}{ 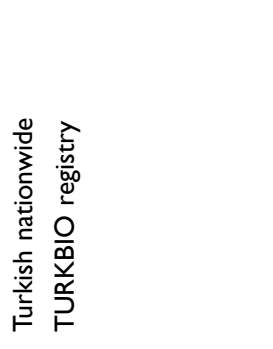 } \\
\hline 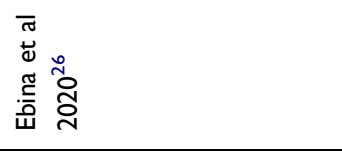 & 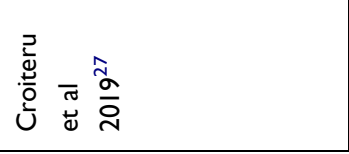 & \multicolumn{2}{|l|}{ 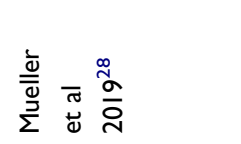 } & \multicolumn{2}{|l|}{ 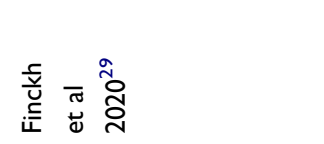 } & \multicolumn{2}{|l|}{ 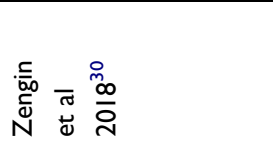 } \\
\hline
\end{tabular}




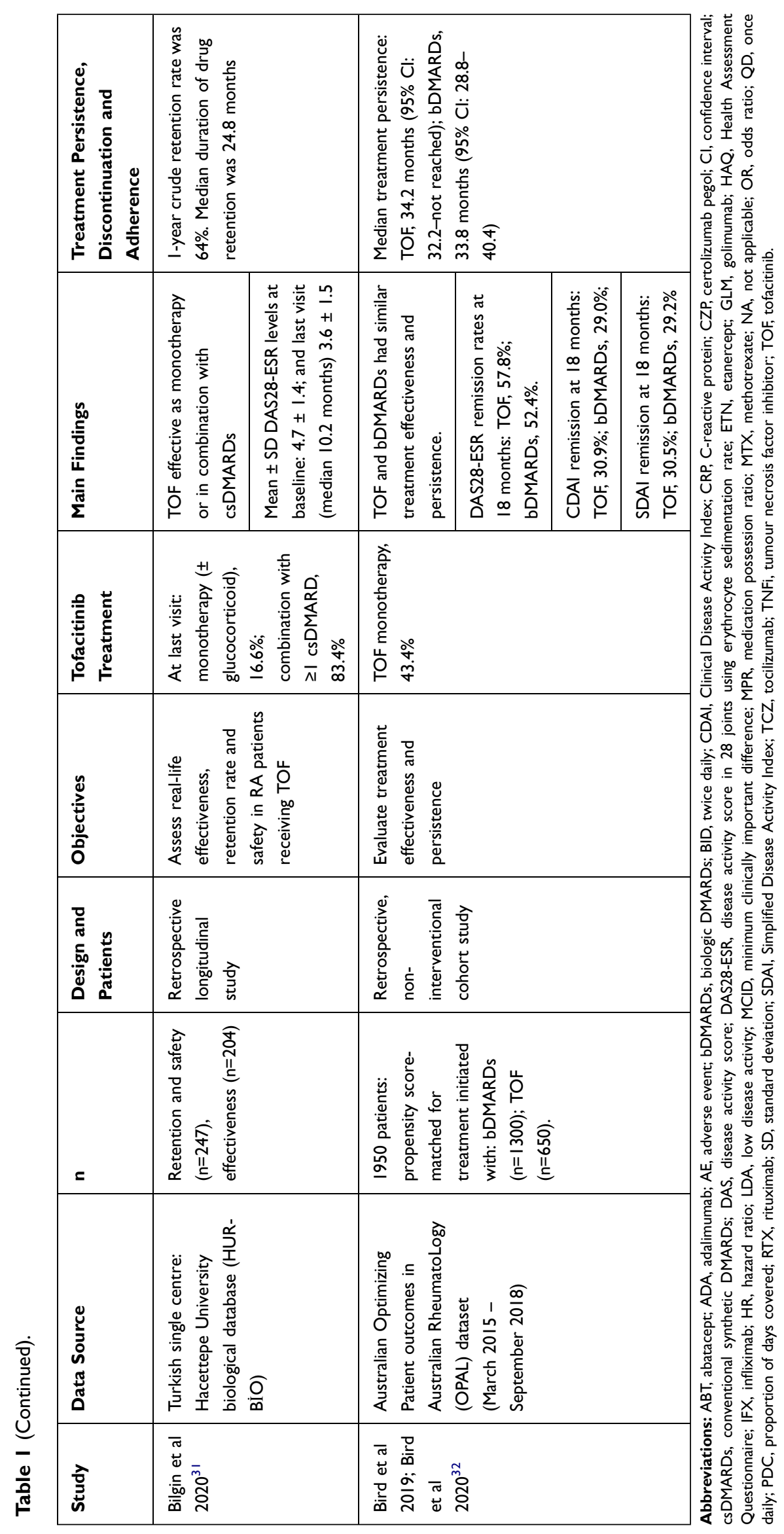


tofacitinib MR compared with the IR formulation. Duration of treatment was comparable for both formulations.

A Canadian study of IBM MarketScan Research databases with data from the US found that new tofacitinib users $(\mathrm{n}=1031)$ had shorter medication persistence compared to new bDMARD patients $(\mathrm{n}=17,803) .{ }^{21}$ Median persistence was 0.81 vs 1.02 years, respectively, and the adjusted hazard ratio (HR) for discontinuation of tofacitinib compared with bDMARDs was 1.14 (95\% CI: 1.05-1.25). However, patients who switched from a bDMARD to tofacitinib had longer persistence than those who switched from one bDMARD to another agent: adjusted HR for discontinuation was 0.90 (95\% CI: 0.83-0.97).

A Canadian study from the Ontario Best Practices Research Initiative (OBRI) in patients initiating tofacitinib $(\mathrm{n}=208)$ or TNFi $(\mathrm{n}=357)$, reported discontinuation rates of $36 \%$ and $29 \%$, respectively, during a mean follow-up of 17.3 months. $^{22}$ Discontinuation rates in patients receiving tofacitinib monotherapy or in combination with MTX were similar.

Data from the Canadian eXel programme reported a discontinuation rate for tofacitinib initiators $(n=3678)$ of $33.3 \%$, which was due to ineffectiveness in $35.7 \%$ of cases, adverse events (AEs) in $26.9 \%$, and patient decision to try another therapy in $12.0 \%$ of cases. ${ }^{23}$ Temporary cessation was observed in $7.7 \%$ of patients. Persistence rates at 1 and 2 years were $62.7 \%$ and $49.6 \%$, respectively (defined as percentage of patients remaining on tofacitinib after receiving $\leq 1$ dose). Median drug survival in bDMARD-naïve, post-1 bDMARD, post-2 bDMARD and post $-\geq 3$ bDMARD patients, was $>730,613,667$ and 592 days, respectively. An increased likelihood of tofacitinib persistence was associated with bDMARD-naïvity (vs bDMARD-experienced; $\mathrm{p}<0.001$ ), increased aged $(\geq 56$ vs $\leq 45$ years; $p<0.05)$ and time since diagnosis of $15-19$ years (vs $<5$ years; $\mathrm{p}<0.01$ ).

A single centre Japanese study of RA patients $(\mathrm{n}=100)$ found that after year 1 of tofacitinib treatment, $53 \%$ achieved remission and a further $15 \%$ had low disease activity (CDAI $<2.8$ and $\leq 10)$. The 1 -year discontinuation rate was $32 \%$ (ineffectiveness $24 \%$, AEs $4 \%$ and patient preference $4 \%){ }^{24}$ Interim analysis of postmarketing surveillance of tofacitinib in Japan reported that during the first 6 months of study, $22.7 \%$ of all patients $(n=3929)$ discontinued treatment mainly due to AEs $(8.9 \%)$ and lack of efficacy $(8.5 \%){ }^{25}$

The Japanese ANSWER retrospective study of registry data compared drug retention for 7 bDMARDs and tofacitinib in biologic-naïve and biologic-experienced RA patients. $^{26}$ For tofacitinib, data were available for 101 patients who were switched from a bDMARD. Drug discontinuation rates due to lack of effectiveness differed significantly between the 8 agents in bDMARD-switched patients $(\mathrm{p}<0.001)$, ranging from relatively low values for tocilizumab (18.9\%) and tofacitinib (22.8\%) to $46.1 \%$ for certolizumab pegol. Drug discontinuation rates due to remission were comparable and ranged from $1.1 \%$ for certolizumab pegol to $3.3 \%$ for golimumab, and with $2.3 \%$ for tofacitinib.

Analysis of Israeli RA registry data on 864 treatment courses compared persistence for four bDMARDs and tofacitinib. ${ }^{27}$ Median drug persistence for tofacitinib was 15.8 months (95\% CI: 8.6-23.1) and was non-inferior to etanercept (26.4 months, 95\% CI: 5.9-46.9; $\mathrm{p}=0.426$ ), abatacept (20.3 months, 95\% CI: 9.8-30.9; $\mathrm{p}=0.157)$ and golimumab (15.1 months, 95\% CI: 5.9-24.3; p = 0.698). Compared with tofacitinib, etanercept, abatacept and golimumab, tocilizumab had a significantly higher retention rate (HR for drug survival vs tofacitinib was $1.92,95 \% \mathrm{CI}$ : 1.33-2.76), but tofacitinib was mostly prescribed as third or later line of therapy (64\%)

A Swiss retrospective study of the St. Gallen and Aarau Cohorts assessed tolerability and effectiveness in patients initiated on tofacitinib $(\mathrm{n}=144) .{ }^{28}$ Tofacitinib significantly reduced mean DAS28 from 4.4 at baseline to 3.13 at 360 days; $53 \%$ of patients achieved LDA and $48 \%$ DAS28-defined remission. The rates of LDA and remission for tofacitinib were higher in biologic-naïve patients compared to those who had previous biologic exposure: $100 \%$ of biologic-naïve patients achieved LDA, and $83.3 \%$ achieved remission, compared with $53.3 \%$ and $44.9 \%$ of patients pre-exposed to biologics. The discontinuation rate during a mean of 1.22 years follow-up was $38.2 \%$ which was attributable to AEs (23.6\%) and insufficient response (14.6\%).

Analysis of the Swiss Clinical Quality Management in Rheumatoid Arthritis (SCQM-RA) Registry found that drug maintenance in tofacitinib initiators $(n=806)$ was significantly higher than TNFi initiators $(n=1862)$ and comparable with non-TNFi bDMARDs (eg, rituximab, tocilizumab, abatacept) initiators $(\mathrm{n}=1355)$. Median (IQR) drug maintenance was 25 months (19-30) for tofacitinib, 19 months (17-22) for non-TNFi bDMARDs and 17 months (15-18) for TNFi. The adjusted HR for drug discontinuation with TNFi compared with tofacitinib was 1.29 (95\% CI: 1.14-1.47) and was 1.09 (95\% CI: $0.96-$ 
1.24) for both non-TNFi bDMARDs and tofacitinib. Discontinuation was most commonly due to ineffectiveness with lower rates for tofacitinib (46\%) compared with non-TNFi bDMARDs (50\%) and TNFi (57\%). ${ }^{29}$

A retrospective analysis of RA patients $(n=180)$ in the Turkish nationwide TURKBIO registry showed that tofacitinib significantly reduced VAS pain scores, DAS28, HAQ and C-reactive protein (CRP) from baseline to week $60 .{ }^{30}$ Tofacitinib persistence rates were $75 \%$ at 48 weeks and $48 \%$ at 137 weeks. The main reasons for tofacitinib discontinuation were ineffectiveness (63\%) and AEs (23\%). In a Turkish single centre study $(n=204)$, tofacitinib reduced mean \pm SD DAS28-ESR levels from $4.7 \pm 1.4$ at baseline to $3.6 \pm 1.5$ at last visit (median 10.2 months); tofacitinib had a 1 -year crude retention rate of $64 \%$ and a median duration of drug retention of 24.8 months. $^{31}$

Analysis of the Australian Optimizing Patient outcomes in Australian RheumatoLogy (OPAL) dataset used propensity score matching at a ratio of 1:2 to compare with tofacitinib $(n=650)$ and bDMARDs $(n=1300) .{ }^{32}$ Similar DAS remission rates at 18 months were reported for tofacitinib (57.8\%) and bDMARDs (52.4\%) and the proportion of patients achieving CDAI or SDAI remission was similar with respective rates of $30.9 \%$ and $30.5 \%$ for tofacitinib, and $29.2 \%$ and $29.0 \%$ for bDMARDs. Median treatment persistence was similar for tofacitinib (34.2 months; 95\% CI: 32.2-not reached) and bDMARDs (33.8 months; 95\% CI: 28.8-40.4).

\section{Safety}

Results from real-world studies on the safety and tolerability of tofacitinib are summarised in Table 2. A prospective, observational study of US Corrona RA registry data evaluated 5-year AE incidence rates in propensity score trimmed tofacitinib $(\mathrm{n}=1117)$ and bDMARD $(\mathrm{n}=5542)$ initiators. $^{33}$ The most common AEs in an interim analysis (first 6-month observation period) of a 3-year study post-marketing surveillance of tofacitinib $(\mathrm{n}=3929)$ in Japan were herpes zoster $(3.7 \%)$ and abnormal hepatic function (1.8\%). Serious AEs were reported in 287 patients $(7.3 \%)$, commonly herpes zoster $(0.6 \%)$ and pneumonia/bacterial pneumonia $(0.8 \%){ }^{34}$ A retrospective study of Swiss Cohorts $(n=144)$ found a discontinuation rate due to AEs of $23.6 \%$ which was comparable to that reported in the ORAL Sequel LTE study (25\%). ${ }^{12}$ Gastrointestinal symptoms (12.5\%) were the main reason for stopping treatment in the Swiss
Cohorts. ${ }^{28}$ A retrospective Turkish single centre study found that tofacitinib was well tolerated and had a discontinuation rate due to AEs of $15.0 \%$, most commonly due to allergic skin reactions $(2.4 \%)$. The most common infectious and laboratory AEs were herpes zoster (3.9 per 100 patient-years) and ALT elevation (9.7 per 100 patient-years), respectively. ${ }^{31}$

\section{Thrombosis/Cardiovascular Disease (CVD)}

Retrospective analysis of the US FORWARD database spanning 20 years, which included 17,363 RA patients, compared the CVD risk with biologics and tofacitinib to csDMARDs. ${ }^{35}$ The study found a significant reduction in CVD risk with TNFi and abatacept, a non-significant reduction with tofacitinib and a significant increase with glucocorticoids. Adjusted HRs for CVD vs csDMARDs were: TNFi, 0.79 (95\% CI: 0.69-0.92), abatacept, 0.53 (95\% CI: 0.30-0.92); tofacitinib, 0.33 (95\% CI: $0.05-$ 2.38); rituximab, 0.78 (95\% CI: 0.41-1.47); tocilizumab, 1.00 (95\% CI: 0.44-2.27); anakinra, 0.87 (95\% CI: $0.32-$ 2.33); and glucocorticoids, 1.15 (95\% CI: 1.11-1.20).

In the US Corrona RA registry, incidence rates of MACE and VTE were comparable for tofacitinib and bDMARDs initiators. ${ }^{33}$ This prospective, observational, 5-year analysis examined data from 1544 initiators of tofacitinib (2138 patient-years) and 7083 bDMARD (9905 patient-years) initiators. The adjusted HR for MACE for both cohorts was 0.60 (95\% CI: 0.30-1.18). Rates of VTE were also similar between tofacitinib and bDMARDs.

Analysis of US Marketscan claims databases found comparable risks for VTE in patients initiating treatment with tofacitinib $(n=2155)$ or adalimumab $(n=6022) .{ }^{36}$ After a median follow-up of 0.5 years, the VTE incidence rate for tofacitinib was 1.31 per 100 patient-years $(95 \%$ CI: 0.80-2.03) and for adalimumab was 0.83 per 100 patient-years (95\% CI: 0.60-1.14). ${ }^{36}$

Analysis of US Truven MarketScan $(n=34,074)$ and Medicare claims $(n=17,086)$ databases found no significant difference in the risk of VTE between tofacitinibtreated and TNFi-treated patients. ${ }^{37}$ The crude incidence rate of VTE in the Truven database for tofacitinib was 0.60 per 100 person-years (95\% CI: 0.26-1.19) and for TNFi was 0.34 (95\% CI: $0.27-0.41)$; in the Medicare database it was 1.12 (95\% CI: $0.45-2.31)$ and 0.92 (95\% CI: $0.76-1.11)$, respectively. ${ }^{37}$ 


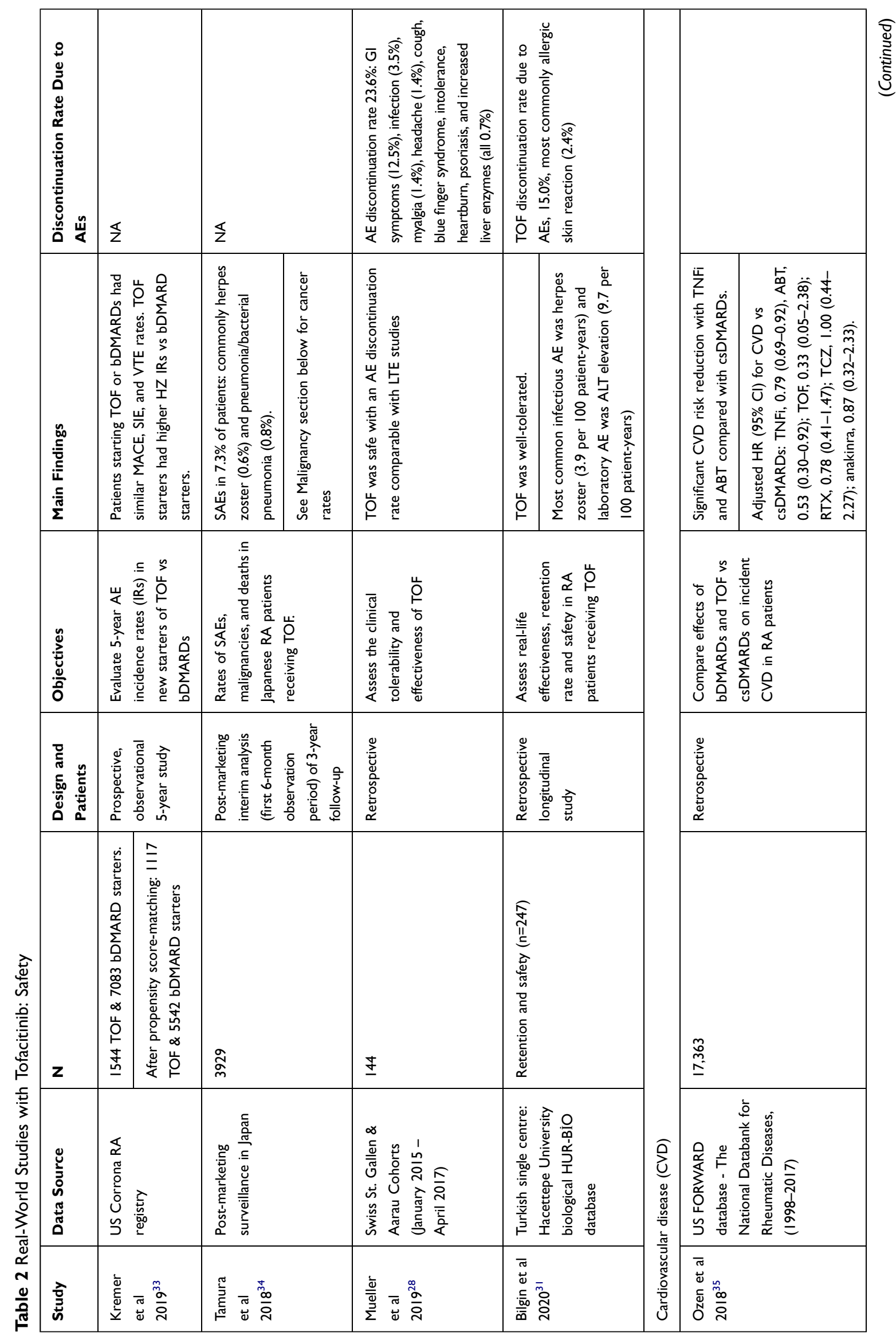




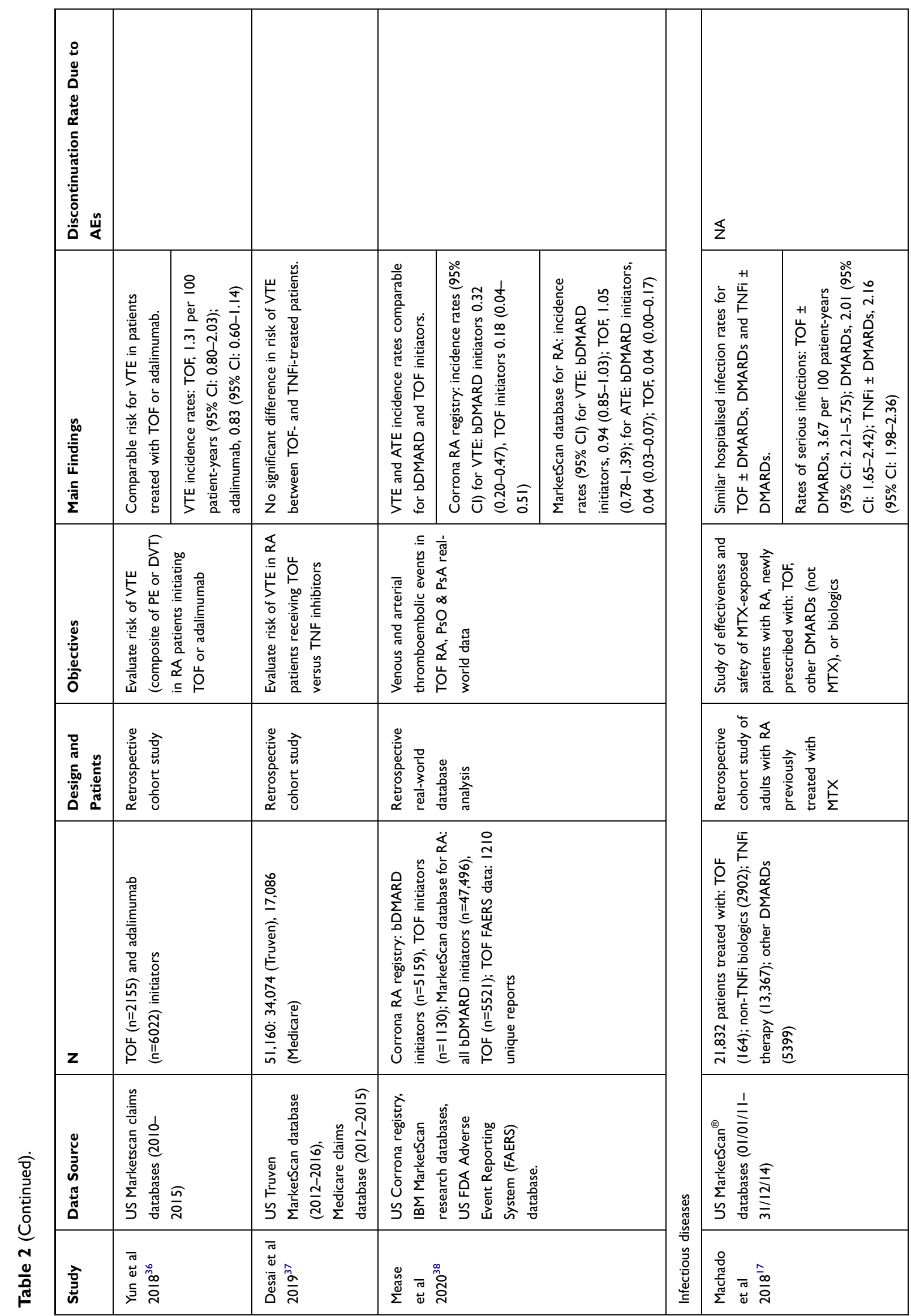




\begin{tabular}{|c|c|c|c|c|c|c|}
\hline 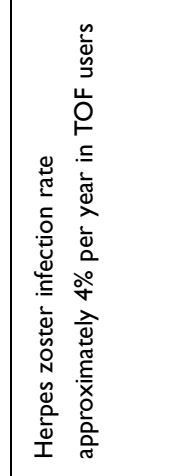 & 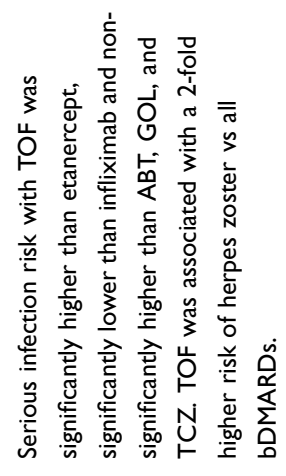 & 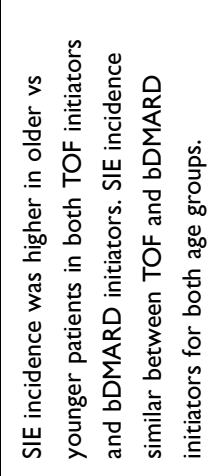 & 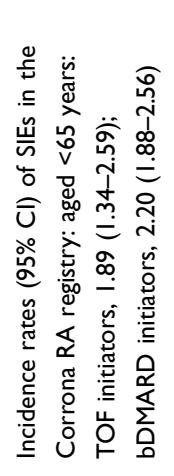 & 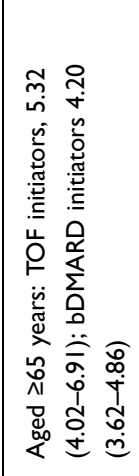 & 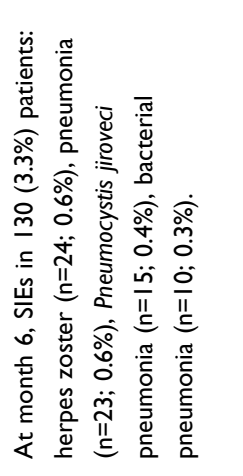 & 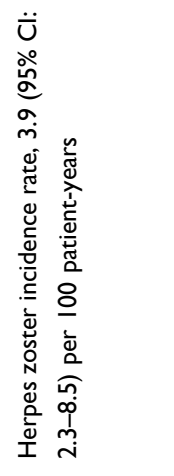 \\
\hline 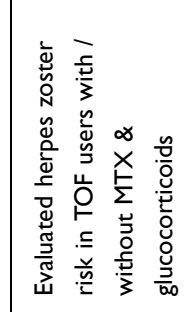 & 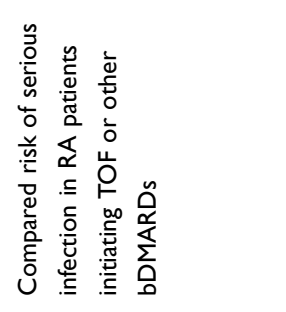 & 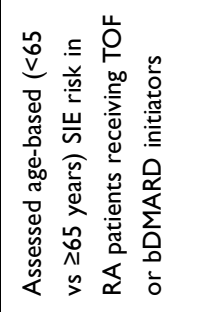 & & & 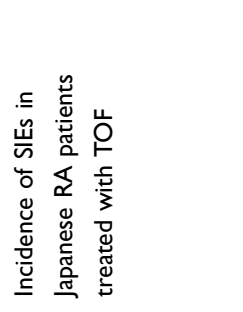 & 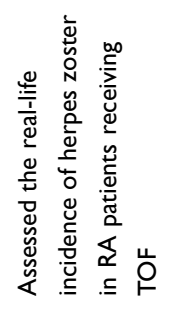 \\
\hline 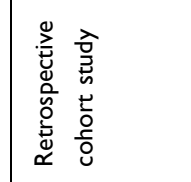 & 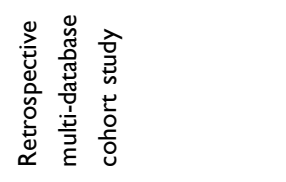 & 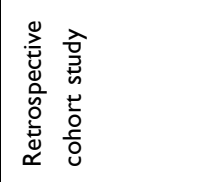 & & & 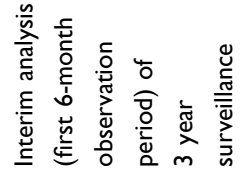 & 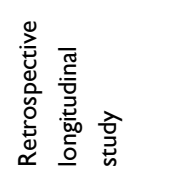 \\
\hline 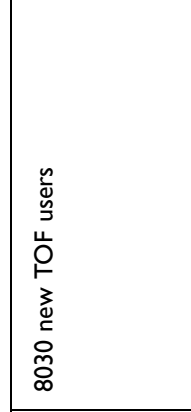 & 类 & 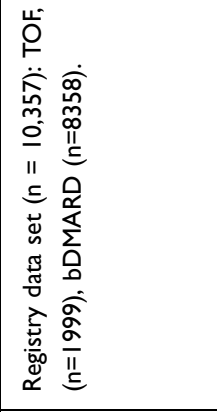 & & & స్ & d \\
\hline 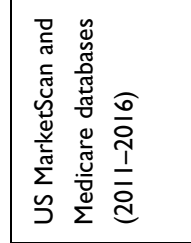 & 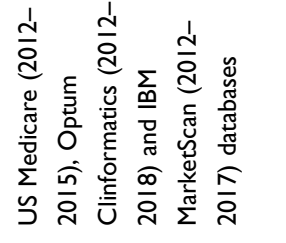 & 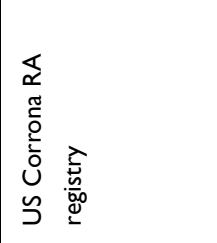 & & & 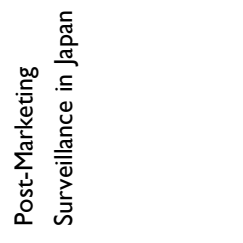 & 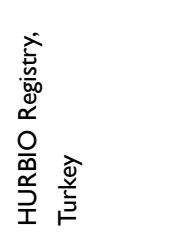 \\
\hline 党 & 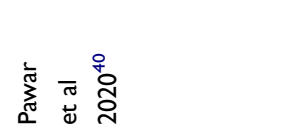 & 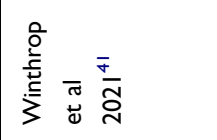 & & & 惡 & 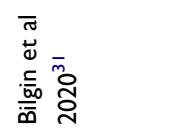 \\
\hline
\end{tabular}




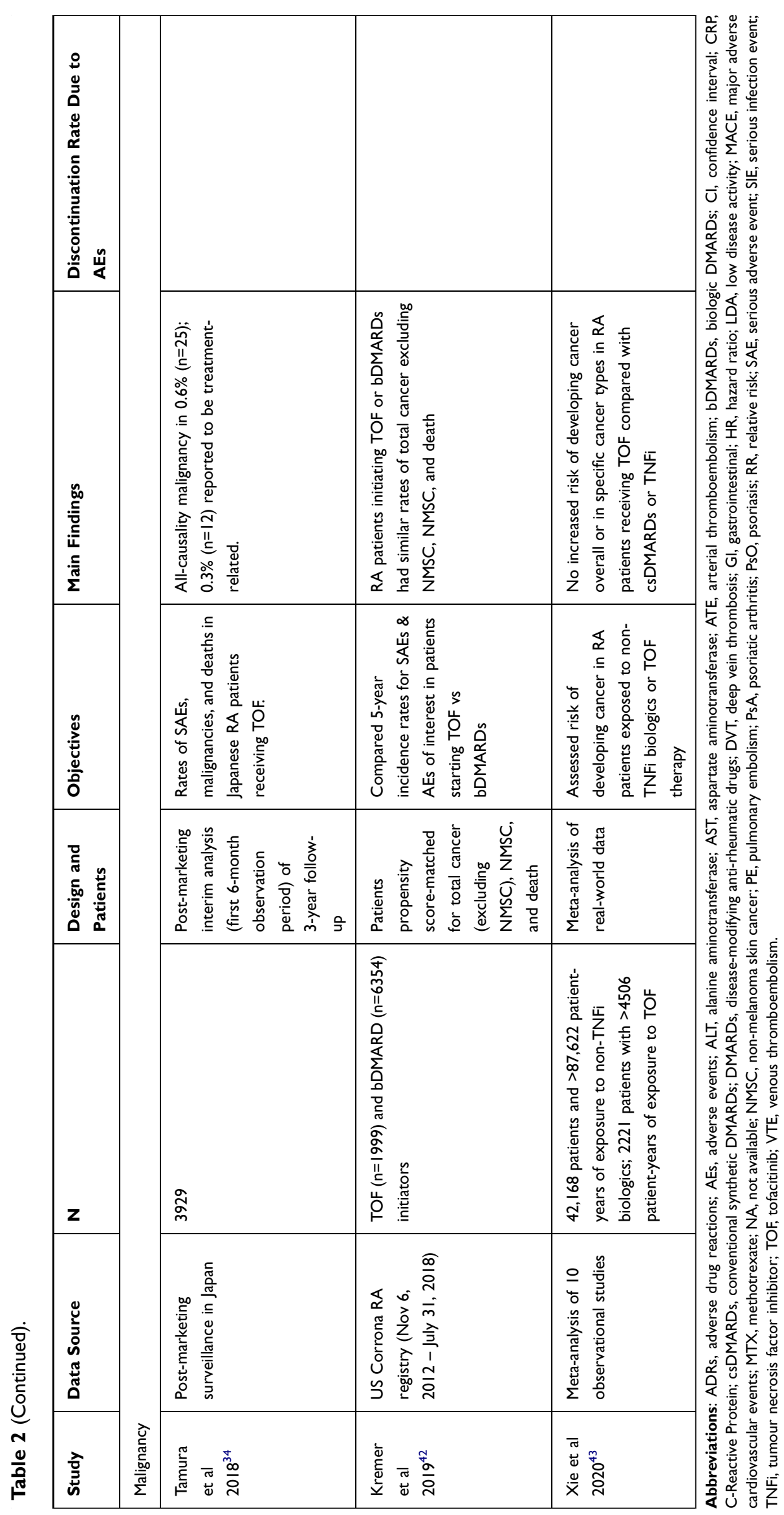


Mease et al 2020 reported observational data from the US Corrona registries (including cardiovascular risk factor stratification), IBM MarketScan research databases and the US FDA Adverse Event Reporting System (FAERS) database as well as results from separate RA, psoriasis ( $\mathrm{PsO}$ ) and psoriatic arthritis (PsA) development programmes for tofacitinib $5 \mathrm{mg}$ vs $10 \mathrm{mg} \mathrm{BID.}{ }^{38}$ Incidence rates of deep vein thrombosis (DVT), pulmonary embolism (PE) and arterial thromboembolism (ATE) in the tofacitinib RA, PsO and PsA programmes were similar across tofacitinib doses, and were generally consistent with the real-world data. In the Corrona RA registry, the VTE incidence rate for bDMARD initiators was 0.32 per 100 patient-years' exposure (95\% CI: $0.20-0.47)$ and 0.18 (95\% CI: $0.04-0.51)$ for tofacitinib initiators. In the MarketScan databases for RA, incidence rates of VTE were 0.94 (95\% CI: $0.85-1.03)$ and 1.05 (95\% CI: 0.78-1.39), respectively. Respective incidence rates for ATE were $0.04(95 \% \mathrm{CI}$ : $0.03-0.07)$ and 0.04 (95\% CI: 0.00-0.17), respectively. ${ }^{38}$

\section{Infections}

Retrospective analysis of US MarketScan ${ }^{\circledR}$ databases of adults with RA previously treated with MTX $(n=21,832)$ found similar hospitalised infection rates for tofacitinib \pm DMARDs, DMARDs and TNFi \pm DMARDs. ${ }^{17}$ Rates of serious infections were: tofacitinib \pm DMARDs, 3.67 per 100 patient-years (95\% CI: 2.21-5.75); DMARDs, 2.01 (95\% CI: 1.65-2.42); and TNFi \pm DMARDs, 2.16 (95\% CI: $1.98-2.36)$.

Retrospective analysis of US MarketScan and Medicare databases of new users of tofacitinib ( $\mathrm{n}=$ 8030) with or without MTX and glucocorticoids estimated the herpes zoster infection rate as approximately $4 \%$ per year. ${ }^{39}$

Analysis of multiple databases in the US reported that serious infection risk with tofacitinib was significantly higher than with etanercept, significantly lower than with infliximab, non-significantly higher than with abatacept, golimumab and tocilizumab, and similar to adalimumab and certolizumab. ${ }^{40}$ Adjusted HRs for serious infection for tofacitinib vs bDMARDs were: vs etanercept, 1.41 (95\% CI 1.15-1.73); vs infliximab, 0.81 (95\% CI: $0.65-1.00)$ vs abatacept, 1.20 (95\% CI: 0.97-1.49); vs golimumab, 1.23 (95\% CI: $0.94-1.62$ ); tocilizumab, 1.17 (95\% CI: $0.89-1.53$ ); vs adalimumab, 1.06 (0.87-1.30); vs certolizumab pegol, 1.02 (95\% CI: $0.80-1.29)$.

In the US Corrona RA registry, the adjusted HR for SIEs was 0.99 (95\% CI: 0.72-1.36), and tofacitinib initiators had higher rates of herpes zoster compared with
bDMARD initiators for a significantly increased adjusted HR (2.12; 95\% CI: 1.22-3.66). ${ }^{33}$ All herpes zoster events with tofacitinib were non-serious. When stratified by age ( $<65$ vs $\geq 65$ years), the incidence of serious infections with tofacitinib vs bDMARDs was higher in older patients for both tofacitinib initiators and bDMARD initiators and similar between tofacitinib and bDMARD initiators for both age groups. ${ }^{41}$

All-case post-marketing surveillance in Japanese patients with RA treated with tofacitinib reported that 6-month serious infection events occurred in 130 (3.3\%) patients, most commonly herpes zoster $(0.6 \%)$ and pneumonia $(0.6 \%){ }^{25}$

Assessment of the risk for herpes zoster in tofacitinibtreated RA patients, with or without concomitant methotrexate and glucocorticoids, reported an infection rate of approximately $4 \%$ per year. $^{39}$

\section{Malignancy}

The prospective, observational, 5-year analysis of the US Corrona RA registry examined data from 1999 patients initiating tofacitinib (4505.62 patient-years) and 6354 initiating a bDMARD $\left(16,670.84\right.$ patient-years). ${ }^{42}$ In the entire population, HRs were: for total cancer (excluding NMSC), 1.04 (95\% CI: 0.68-1.61); NMSC, 1.02 (95\% CI: $0.69-1.50)$; and death, 1.0 (95\% CI: $0.62-1.63) .{ }^{42}$ Similar rates of all cancers (excluding NMSC), NMSC and death were seen for tofacitinib and bDMARDs. ${ }^{42}$

Interim (6-month) post-marketing surveillance of malignancy in Japanese RA patients treated with tofacitinib reported all-causality malignancy in 25 patients $(0.6 \%)$, of which 12 were considered to be treatmentrelated. ${ }^{34} \mathrm{~A}$ total of 21 deaths $(0.5 \%)$ occurred during the 6-month period, most commonly due to infection $(\mathrm{n}=6$; $0.15 \%)$ and malignancy $(\mathrm{n}=5 ; 0.13 \%)$. Over 36 months, malignancy was reported in 61 patients (4874 patientyears) with a cumulative incidence rate of $1.25 / 100$ patient-years. Rates of malignancies and death were comparable with those in the tofacitinib RA clinical programme and no new or unexpected safety risks were identified.

A meta-analysis of observational studies assessed the risk of malignancy with non-TNFi biologic or tofacitinib therapy in RA. ${ }^{43}$ The analysis, including 10 studies and involving 42,168 patients and >87,622 patient-years of exposure to non-TNFi biologics, included 2221 patients with $>4506$ patient-years of exposure to tofacitinib. There was no increased risk of developing cancer overall or in 
specific cancer types in RA patients receiving tofacitinib compared with those receiving csDMARDs or TNFi.

\section{Discussion}

Drug retention rates may differ markedly between different bDMARDs. ${ }^{44-48}$ Several factors affecting bDMARD drug retention rates have been reported, although some appear to be drug- or drug class-specific. For tofacitinib, bDMARD-naïvity (compared with prior bDMARD experience), older age ( $\geq 56$ vs $\leq 45$ years) and longer time since diagnosis $(15-19$ vs $<5$ years) significantly increased the likelihood of drug retention in a study from Canada, ${ }^{23}$ but these findings wait further confirmation. Future real-world studies may delineate other predictors of tofacitinib drug retention.

Discontinuation rates due to ineffectiveness were slightly lower with tofacitinib (46\%) than non-TNFi bDMARDs (50\%) and TNFi (57\%), but rates due to intolerance or AEs were comparatively higher with tofacitinib: $30 \%$ versus $22 \%$ and $19 \%$, respectively. In these analyses of Swiss Registry data, median drug maintenance was longer for tofacitinib (25 months), than non-TNFi bDMARDs (19 months) and TNFi (17 months). ${ }^{29}$ In contrast, a retrospective, non-interventional cohort analysis of the Australian OPAL dataset (derived from 42 rheumatology clinics in Australia, collecting information from individual clinicians' servers during routine clinical consultations) reported similar median treatment persistence of approximately 34 months for tofacitinib compared with bDMARDs. ${ }^{32}$ A previous review of real-world studies (up to mid-2018) found that treatment persistence and adherence to tofacitinib was good overall and similar to those seen for bDMARDs. ${ }^{16}$ RA patients initiating tofacitinib usually had longer disease duration and had been exposed to longer bDMARDs than patients initiating a bDMARD. Real-world data demonstrate the value of monotherapy with tofacitinib, showing the drug retention rate is not affected when in association with MTX, differently than bDMARDs, ${ }^{22}$ and the effectiveness of tofacitinib as monotherapy appears similar to tofacitinib in combination therapy, in contrast to anti-TNF agents. ${ }^{18}$

There is growing evidence of the safety of JAK inhibitors in patients with RA. ${ }^{49}$ Evaluation of the risks of relatively rare serious AEs such as VTE, gastrointestinal perforation and interstitial lung disease in clinical practice requires the accumulation of cases with these events. Continuous pharmacovigilance activity is essential to establish the safety of JAK inhibitors in patients with RA and other rheumatic diseases. ${ }^{49}$

Patients with RA have increased risk of CVD. Observational studies suggest that in the general population and non-RA controls, there are 0.1-0.4 thromboembolic events per 100 patient-years. In RA, thromboembolic risks increase to $0.3-0.7$ per 100 patient-years. ${ }^{50,51}$ Interestingly, a recent meta-analysis of patients with immune-mediated inflammatory diseases $(n=13,611)$ enrolled in RCTs $(n=29)$ found that tofacitinib had analogous rates of all cardiovascular events (odds ratio $[\mathrm{OR}]=1.07,95 \% \mathrm{CI}$ : 0.49-2.34), MACE (OR $=1.54,95 \%$ CI: $0.42-5.59)$ and allcause mortality (OR $=1.13,95 \%$ CI: $0.26-4.95)$ compared with placebo, but a decreased rate of VTEs (OR $=0.03,95 \%$ CI: $0.00-0.21) .{ }^{52}$ Similarly, a meta-analysis of patients with immune-mediated inflammatory diseases enrolled in RCTs (n $=42$ ) reported no increased risk of VTE for JAK inhibitors as a group (6542 patient exposure years) compared with placebo (1578 patient exposure years). ${ }^{53}$ Data pooled from six phase 3 and two long-term extension studies of tofacitinib in RA patients over 7 years, identified 52 MACE occurring in 4076 patients during 12,873 patient-years of exposure for an incidence rate of 0.4 per 100 patient-years. ${ }^{54}$ Additionally, a systematic literature review on 33 clinical trials, 39 prospective and 18 retrospective real-world studies, concluded that there were no indications of a significant increase in adverse cardiovascular events for bDMARDs and tofacitinib in patients with rheumatic diseases. ${ }^{55}$

Importantly, data from a recently completed large randomized prospective post-authorization safety study comparing tofacitinib with anti-TNF therapy in patients with RA who were aged $\geq 50$ years and had $\geq 1$ additional CV risk factor showed an increased rate for tofacitinib relative to anti-TNF therapy regarding venous thromboembolic events (VTE) and major adverse cardiovascular events. ${ }^{56,57}$ Given that the underlying mechanism(s) for these adverse events remain unknown, the effect of JAK inhibitors on CVD risk requires further research.

The utility of real-world evidence for informing healthcare policymakers when making appropriate decisions about treatment pathways has been recognised. ${ }^{58}$ This review of tofacitinib considering recent real-world evidence provides an update from a previous review which included studies up to mid-2018. ${ }^{16}$ These retrospective and prospective observational studies have demonstrated the effectiveness of tofacitinib and reinforce data from the pivotal clinical trial programme. Treatment persistence was generally comparable to that of bDMARDs, and the 
safety findings in these observational studies were consistent with the known safety profile of the approved dose of $5 \mathrm{mg}$ BID.

\section{Acknowledgments}

Medical writing support was provided by Robert A. Furlong $\mathrm{PhD}$ and David P. Figgitt $\mathrm{PhD}$, ISMPP CMPPтм, on behalf of Content Ed Net Spa. This support was funded by Pfizer Italy.

\section{Funding}

Writing support was funded by Pfizer Italy.

\section{Disclosure}

Roberto Caporali received an honorarium from Pfizer in connection with the development of this manuscript. Roberto Caporali reports personal fees from Abbvie, Roche, Celltrion, BMS, Amgen, Lilly, Galapagos, Sanofi, and UCB, during the conduct of the study. Ilaria Bertoldi is a Pfizer employee.

\section{References}

1. Smolen JS, Landewe RBM, Bijlsma JWJ, et al. EULAR recommendations for the management of rheumatoid arthritis with synthetic and biological disease-modifying antirheumatic drugs: 2019 update. Ann Rheum Dis. 2020;79:685-699. doi:10.1136/annrheumdis-2019-216655

2. Hodge JA, Kawabata TT, Krishnaswami S, et al. The mechanism of action of tofacitinib - an oral Janus kinase inhibitor for the treatment of rheumatoid arthritis. Clin Exp Rheumatol. 2016;34:318-328.

3. Schwartz DM, Kanno Y, Villarino A, Ward M, Gadina M, O'shea JJ. JAK inhibition as a therapeutic strategy for immune and inflammatory diseases. Nat Rev Drug Discov. 2017;16:843-862. doi:10.1038/nrd.2017.201

4. Burmester GR, Blanco R, Charles-Schoeman C, et al. Tofacitinib (CP-690,550) in combination with methotrexate in patients with active rheumatoid arthritis with an inadequate response to tumour necrosis factor inhibitors: a randomised phase 3 trial. Lancet. 2013;381:451-460. doi:10.1016/S0140-6736(12)61424-X

5. Fleischmann R, Kremer J, Cush J, et al. Placebo-controlled trial of tofacitinib monotherapy in rheumatoid arthritis. $N$ Engl $J$ Med. 2012;367:495-507. doi:10.1056/NEJMoa1109071

6. Fleischmann R, Mysler E, Hall S, et al. Efficacy and safety of tofacitinib monotherapy, tofacitinib with methotrexate, and adalimumab with methotrexate in patients with rheumatoid arthritis (ORAL Strategy): a phase $3 \mathrm{~b} / 4$, double-blind, head-to-head, randomised controlled trial. Lancet. 2017;390:457-468. doi:10.1016/S0140-6736(17)31618-5

7. Kremer J, Li ZG, Hall S, et al. Tofacitinib in combination with nonbiologic disease-modifying antirheumatic drugs in patients with active rheumatoid arthritis: a randomized trial. Ann Intern Med. 2013;159:253-261. doi:10.7326/0003-4819-159-4-201308200-00006

8. Lee EB, Fleischmann R, Hall S, et al. Tofacitinib versus methotrexate in rheumatoid arthritis. $N$ Engl $J$ Med. 2014;370:2377-2386. doi:10.1056/NEJMoa1310476

9. Van Der Heijde D, Strand V, Tanaka Y, et al. Tofacitinib in combination with methotrexate in patients with rheumatoid arthritis: clinical efficacy, radiographic, and safety outcomes from a twenty-four-month, phase III study. Arthritis Rheumatol. 2019;71:878-891. doi:10.1002/ art.40803
10. Van Der Heijde D, Tanaka Y, Fleischmann R, et al. Tofacitinib (CP-690,550) in patients with rheumatoid arthritis receiving methotrexate: twelve-month data from a twenty-four-month phase III randomized radiographic study. Arthritis Rheumatol. 2013;65:559-570. doi:10.1002/art.37816

11. Van Vollenhoven RF, Fleischmann R, Cohen S, et al. Tofacitinib or adalimumab versus placebo in rheumatoid arthritis. $N$ Engl $J$ Med. 2012;367:508-519. doi:10.1056/NEJMoa1112072

12. Wollenhaupt J, Lee EB, Curtis JR, et al. Safety and efficacy of tofacitinib for up to 9.5 years in the treatment of rheumatoid arthritis: final results of a global, open-label, long-term extension study. Arthritis Res Ther. 2019;21:89. doi:10.1186/s13075-019-1866-2

13. Barnish MS, Turner S. The value of pragmatic and observational studies in health care and public health. Pragmat Obs Res. 2017;8:49-55. doi:10.2147/POR.S137701

14. Bartlett VL, Dhruva SS, Shah ND, Ryan P, Ross JS. Feasibility of using real-world data to replicate clinical trial evidence. JAMA Netw Open. 2019;2:e1912869. doi:10.1001/jamanetworkopen.2019.12869

15. Monti S, Grosso V, Todoerti M, Caporali R. Randomized controlled trials and real-world data: differences and similarities to untangle literature data. Rheumatology (Oxford). 2018;57:vii54-vii8. doi:10.1093/rheumatology/key109

16. Caporali R, Zavaglia D. Real-world experience with tofacitinib for the treatment of rheumatoid arthritis. Clin Exp Rheumatol. 2019;37:485-495.

17. Machado MAA, Moura CS, Guerra SF, Curtis JR, Abrahamowicz M, Bernatsky S. Effectiveness and safety of tofacitinib in rheumatoid arthritis: a cohort study. Arthritis Res Ther. 2018;20:60. doi:10.1186/ s13075-018-1539-6

18. Reed GW, Gerber RA, Shan Y, et al. Real-world comparative effectiveness of tofacitinib and tumor necrosis factor inhibitors as monotherapy and combination therapy for treatment of rheumatoid arthritis. Rheumatol Ther. 2019;6(4):573-586. doi:10.1007/s40744019-00177-4

19. Harnett J, Smith T, Woolcott J, Gruben D, Murray C. Impact of TNF inhibitor cycling with adalimumab and etanercept vs switching to tofacitinib [abstract number: 1426]. Arthritis Rheumatol. 2019;71(suppl 10). Available from: https://acrabstracts.org/abstract/impact-of-tnf-inhibitorcycling-with-adalimumab-and-etanercept-vs-switching-to-tofacitinib/.

20. Cohen SB, Greenberg JD, Harnett J, et al. Real-world evidence to contextualize clinical trial results and inform regulatory decisions: tofacitinib modified-release once-daily vs immediate-release twice-daily for rheumatoid arthritis. Adv Ther. 2020;38(1):226-248. doi:10.1007/s12325-020-01501-z

21. Fisher A, Hudson M, Platt RW, Dormuth CR; Canadian Network for Observational Drug Effect Studies (CNODES) Investigators. Tofacitinib persistence in patients with rheumatoid arthritis: a retrospective cohort study. J Rheumatol. 2020;48(1):16-24. doi:10.3899/jrheum.191252

22. Movahedi M, Cesta A, Li X, Keystone E, Bombardier C. Time to discontinuation of tofacitinib in rheumatoid arthritis patients with and without methotrexate: results from a rheumatoid arthritis cohort. Ann Rheum Dis. 2020;79(suppl 1):131. doi:10.1136/annrheumdis-2020-eular.1745

23. Pope J, Bessette L, Jones N, et al. Experience with tofacitinib in Canada: patient characteristics and treatment patterns in rheumatoid arthritis over 3 years. Rheumatology (Oxford). 2020;59:568-574. doi:10.1093/rheumatology/kez324

24. Mori S, Ueki Y. Outcomes of dose reduction, withdrawal, and restart of tofacitinib in patients with rheumatoid arthritis: a prospective observational study. Clin Rheumatol. 2019;38:3391-3400. doi:10.1007/s10067-019-04721-z

25. Tamura N, Kuwana M, Atsumi T, et al. Infection events in Japanese patients with rheumatoid arthritis treated with tofacitinib: interim all-case post-marketing surveillance [abstract number: 1516]. Arthritis Rheumatol. 2018;70(supp110). Available from: https://acrabstracts.org/ abstract/infection-events-in-japanese-patients-with-rheumatoid-arthritistreated-with-tofacitinib-interim-all-case-post-marketing-surveillance/. 
26. Ebina K, Hirano T, Maeda Y, et al. Drug retention of 7 biologics and tofacitinib in biologics-naive and biologics-switched patients with rheumatoid arthritis: the ANSWER cohort study. Arthritis Res Ther. 2020;22:142. doi:10.1186/s13075-020-02232-w

27. Croiteru A, Lidar M, Reitblat T, et al. Real life retention of tofacitinib in patients with rheumatoid arthritis. Arthritis Rheumatol. 2019;71 (suppl 10). Available from: https://acrabstracts.org/abstract/real-liferetention-of-tofacitinib-in-patients-with-rheumatoid-arthritis/.

28. Mueller RB, Hasler C, Popp F, et al. Effectiveness, tolerability, and safety of tofacitinib in rheumatoid arthritis: a retrospective analysis of real-world data from the St. Gallen and Aarau cohorts. J Clin Med. 2019;8:1548. doi:10.3390/jcm8101548

29. Finckh A, Tellenbach C, Herzog L, et al. Comparative effectiveness of antitumour necrosis factor agents, biologics with an alternative mode of action and tofacitinib in an observational cohort of patients with rheumatoid arthritis in Switzerland. RMD Open. 2020;6: e001174. doi:10.1136/rmdopen-2020-001174

30. Zengin B, Inanç N, Akar S, et al. Similar efficacy of tofacitinib on disease activity in rheumatoid arthritis patients with and without previous biologicals; results from the Turkbio registry. Ann Rheum Dis. 2018;77(suppl):A1401.

31. Bilgin E, Ceylan F, Duran E, et al. Efficacy, retention and safety of tofacitinib in real-life: hur-bio monocentric experience. Turk $J$ Med Sci. 2020;51(1):297-308. doi:10.3906/sag-2007-123

32. Bird P, Littlejohn G, Butcher B, et al. Real-world evaluation of effectiveness, persistence, and usage patterns of tofacitinib in treatment of rheumatoid arthritis in Australia. Clin Rheumatol. 2020;39:2545-2551. doi:10.1007/s10067-020-05021-7

33. Kremer JM, Bingham C, Cappelli L, et al. Post-approval comparative safety study of tofacitinib and biologic DMARDs: five-year results from a US-based rheumatoid arthritis registry. Ann Rheum Dis. 2019;78(suppl 2):A82.

34. Tamura N, Kuwana M, Atsumi T, et al. Malignancy in Japanese patients with rheumatoid arthritis treated with tofacitinib: interim analysis of all-case post-marketing surveillance [abstract number: 1515]. Arthritis Rheumatol. 2018;70(suppl10). Available from: https://acrabstracts.org/ abstract/malignancy-in-japanese-patients-with-rheumatoid-arthritistreated-with-tofacitinib-interim-analysis-of-all-case-post-marketingsurveillance/.

35. Ozen G, Pedro S, Michaud K. Cardiovascular disease risk with biologics and tofacitinib compared to conventional synthetic DMARDs in patients with rheumatoid arthritis [abstract number: 2817]. Arthritis Rheumatol. 2018;70(suppl10). Available from: https://acrabstracts.org/abstract/cardi ovascular-disease-risk-with-biologics-and-tofacitinib-compared-toconventional-synthetic-dmards-in-patients-with-rheumatoid-arthritis/.

36. Yun H, Xie F, Chen L, Curtis JR. Risk of venous thrombotic events in rheumatoid arthritis patients initiating tofacitinib or adalimumab [abstract]. Arthritis Rheumatol. 2018;70(supp110). Available from: https://acrabstracts.org/abstract/risk-of-venous-thrombotic-events-inrheumatoid-arthritis-patients-initiating-tofacitinib-or-adalimumab/.

37. Desai RJ, Pawar A, Weinblatt ME, Kim SC. Comparative risk of venous thromboembolism in rheumatoid arthritis patients receiving tofacitinib versus those receiving tumor necrosis factor inhibitors: an observational cohort study. Arthritis Rheumatol. 2019;71:892-900. doi: $10.1002 /$ art.40798

38. Mease P, Charles-Schoeman C, Cohen S, et al. Incidence of venous and arterial thromboembolic events reported in the tofacitinib rheumatoid arthritis, psoriasis and psoriatic arthritis development programmes and from real-world data. Ann Rheum Dis. 2020;79:1400-1413. doi:10.1136/annrheumdis-2019-216761

39. Curtis JR, Xie F, Yang S, et al. Risk for herpes zoster in tofacitinib-treated rheumatoid arthritis patients with and without concomitant methotrexate and glucocorticoids. Arthritis Care Res (Hoboken). 2019;71:1249-1254. doi:10.1002/acr.23769
40. Pawar A, Desai RJ, Gautam N, Kim SC. Risk of admission to hospital for serious infection after initiating tofacitinib versus biologic DMARDs in patients with rheumatoid arthritis: a multidatabase cohort study. Lancet Rheumatol. 2020;2:e84-e98. doi:10.1016/ S2665-9913(19)30137-7

41. Winthrop K, Citera G, Gold D, et al. Age-based ( $<65$ vs $>/=65$ years) incidence of infections and serious infections with tofacitinib versus biological DMARDs in rheumatoid arthritis clinical trials and the US Corrona RA registry. Ann Rheum Dis. 2021;80:134-136. doi:10.1136/annrheumdis-2020-218992

42. Kremer J, Bingham C, Cappelli L, et al. Comparison of malignancy and mortality rates between tofacitinib and biologic DMARDs in clinical practice: five-year results from a US-based rheumatoid arthritis registry [abstract number: 2874]. Arthritis Rheumatol. 2019;71(suppl10). Available from: https://acrabstracts.org/abstract/comparison-ofmalignancy-and-mortality-rates-between-tofacitinib-and-biologicdmards-in-clinical-practice-five-year-results-from-a-us-basedrheumatoid-arthritis-registry/.

43. Xie W, Yang X, Huang H, Gao D, Ji L, Zhang Z. Risk of malignancy with non-TNFi biologic or tofacitinib therapy in rheumatoid arthritis: a meta-analysis of observational studies. Semin Arthritis Rheum. 2020;50:930-937. doi:10.1016/j.semarthrit.2020.08.007

44. Ebina K, Hashimoto M, Yamamoto W, et al. Drug retention and discontinuation reasons between seven biologics in patients with rheumatoid arthritis -the ANSWER cohort study. PLoS One. 2018;13:e0194130. doi:10.1371/journal.pone.0194130

45. Forsblad-D'elia H, Bengtsson K, Kristensen LE, Jacobsson LT. Drug adherence, response and predictors thereof for tocilizumab in patients with rheumatoid arthritis: results from the Swedish biologics register. Rheumatology (Oxford). 2015;54:1186-1193. doi:10.1093/rheumatology/keu 455

46. Gabay C, Riek M, Scherer A, Finckh A, Physicians SC. Effectiveness of biologic DMARDs in monotherapy versus in combination with synthetic DMARDs in rheumatoid arthritis: data from the Swiss Clinical Quality Management Registry. Rheumatology (Oxford). 2015;54:1664-1672. doi:10.1093/rheumatology/kev019

47. Hetland ML, Christensen IJ, Tarp U, et al. Direct comparison of treatment responses, remission rates, and drug adherence in patients with rheumatoid arthritis treated with adalimumab, etanercept, or infliximab: results from eight years of surveillance of clinical practice in the nationwide Danish DANBIO registry. Arthritis Rheumatol. 2010;62:22-32. doi:10.1002/art.27227

48. Souto A, Maneiro JR, Gomez-Reino JJ. Rate of discontinuation and drug survival of biologic therapies in rheumatoid arthritis: a systematic review and meta-analysis of drug registries and health care databases. Rheumatology (Oxford). 2016;55:523-534. doi:10.1093/rheumatology/kev374

49. Harigai M. Growing evidence of the safety of JAK inhibitors in patients with rheumatoid arthritis. Rheumatology (Oxford). 2019;58: i34-i42. doi:10.1093/rheumatology/key287

50. Scott IC, Hider SL, Scott DL. Thromboembolism with Janus Kinase (JAK) inhibitors for rheumatoid arthritis: how real is the risk? Drug Saf. 2018;41:645-653. doi:10.1007/s40264-018-0651-5

51. Yamaoka K. Tofacitinib for the treatment of rheumatoid arthritis: an update. Expert Rev Clin Immunol. 2019;15:577-588. doi:10.1080/ 1744666X.2019.1607298

52. Xie W, Xiao S, Huang Y, Sun X, Zhang Z. Effect of tofacitinib on cardiovascular events and all-cause mortality in patients with immune-mediated inflammatory diseases: a systematic review and meta-analysis of randomized controlled trials. Ther $A d v$ Musculoskelet Dis. 2019;11:1759720X19895492. doi:10.1177/ 1759720X19895492 
53. Yates M, Mootoo A, Adas M, et al. Venous thromboembolism risk with JAK inhibitors: a meta-analysis. Arthritis Rheumatol. 2020;73 (5):779-788. doi:10.1002/art.41580

54. Charles-Schoeman C, Demasi R, Valdez H, et al. Risk factors for major adverse cardiovascular events in phase III and long-term extension studies of tofacitinib in patients with rheumatoid arthritis. Arthritis Rheumatol. 2019;71:1450-1459. doi:10.1002/art.40911

55. Nurmohamed M, Choy E, Lula S, Kola B, Demasi R, Accossato P. The impact of biologics and tofacitinib on cardiovascular risk factors and outcomes in patients with rheumatic disease: a systematic literature review. Drug Saf. 2018;41:473-488. doi:10.1007/s40264-017-0628-9

56. EMA confirms Xeljanz to be used with caution in patients at high risk of blood clots. European Medicines Agency; 2021. Available from: https:/www.ema.europa.eu/en/documents/referral/xeljanz-article-20procedure-ema-confirms-xeljanz-be-used-caution-patients-high-riskblood-clots_en.pdf. Accessed July 17, 2021.
57. Initial safety trial results find increased risk of serious heart-related problems and cancer with arthritis and ulcerative colitis medicine Xeljanz, Xeljanz XR (tofacitinib). US Food And Drug Administration; 2021. Available from: https://www.fda.gov/drugs/ drug-safety-and-availability/initial-safety-trial-results-find-increasedrisk-serious-heart-related-problems-and-cancer-arthritis. Accessed July 17, 2021.

58. Bowrin K, Briere JB, Levy P, Millier A, Clay E, Toumi M. Costeffectiveness analyses using real-world data: an overview of the literature. J Med Econ. 2019;22:545-553. doi:10.1080/ 13696998.2019.1588737

\section{Publish your work in this journal}

Open Access Rheumatology Research and Reviews is an international, peer-reviewed, open access journal publishing original research, reports, editorials, reviews and commentaries on all aspects of clinical and experimental rheumatology in the clinic and laboratory including the following topics: Pathology, pathophysiology of rheumatological diseases; Investigation, treatment and management of rheumatological diseases; Clinical trials and novel pharmacological approaches for the treatment of rheumatological disorders. The manuscript management system is completely online and includes a very quick and fair peer-review system, which is all easy to use. Visit http://www.dovepress.com/testimonials.php to read real quotes from published authors. 